\title{
COMPÓSITO DE GRAMA E POLIURETANO DERIVADO DE ÓLEO DE MAMONA: APLICAÇÕES AO DESIGN DE PRODUTO
}

Biodegradable composites from vegetal fibers and castor oil: applications in Product Design

\author{
Autora: SILVA, Kauhana C.; Graduada ; Universidade Tecnológica Federal do Paraná \\ kauhanas@alunos.utfpr.edu.br \\ Orientador: BELINI, Ugo L.; Doutor; Universidade Tecnológica Federal do Paraná \\ ubelini@utfpr.edu.br \\ Co-orientadora: AZEVEDO, Elaine; Doutora; Universidade Tecnológica Federal do Paraná \\ elainazeve@utfpr.edu.br \\ Co-orientadora: LEITE, Marta K.; Doutora; Universidade Tecnológica Federal do Paraná \\ martaleite@utfpr.edu.br
}

\section{Resumo}

Diante do contexto da busca por materiais ecológicos, que tem resultado no desenvolvimento de compósitos derivados de produtos naturais, este trabalho apresenta dois novos materiais compósitos ecológicos e sua aplicação em Design de Produto, abordando conceitos de Desenvolvimento Sustentável e Ecodesign. Os compósitos de resíduos de grama foram obtidos através da aglutinação das fibras com PU de mamona e prensagem por compressão, onde obtiveram satisfatórias propriedades técnicas após ensaios de caracterização físico-mecânico e análise de imagens sob microscopia eletrônica de varredura (MEV). Posteriormente, foi realizado um brainstorming das possibilidades de aplicações deste compósito, onde foi produzida uma luminária para exemplo de objeto. Dentre as características do produto, destaca-se o visual rústico, a praticidade, a funcionalidade e a sustentabilidade, sendo factível a utilização de grama pós corte para obtenção de compósito aglutinado com PU e sua aplicação no Design de Produto e possíveis produtos para Bioengenharia.

Palavras Chave: Compósito; Sustentabilidade; Grama.

\begin{abstract}
Within the context of the search for ecological materials, which has resulted in development of composites derived from natural products, this paper presents two new ecological composite materials and their application in Product Design, addressing concepts of Sustainable Development and Ecodesign. The composites from the grass residues were obtained through the agglutination of the fibers with PU of castor and compression pressing and obtained appreciable technical properties after physico-mechanical characterization and analysis of images under scanning electron microscopy (SEM). Subsequently, a brainstorming of the possibilities of applications of this composite was realized, where a luminaire was produced for example. As the characteristics of the product, the rustic look, the practicality, the functionality and the sustainability stand out, being possible to use post-cutting grass to obtain PU-bonded composite and its application in Product Design and Bioengineering.
\end{abstract}

Keywords: Composite; Sustainability; Grass. 


\section{INTRODUÇÃO}

A crescente consciência da sociedade com a necessidade de preservação do meio ambiente e a demanda de produtos ecologicamente corretos, resultou na busca por materiais de fontes renováveis envolvendo setores econômicos, sociais e industriais, atrelando estes aspectos ao conceito de Desenvolvimento Sustentável, onde os recursos não são esgotados para o futuro. Para que este desenvolvimento ocorra é necessária qualidade em vez de quantidade, reduzindo o uso de matérias-primas e produtos com aumento da reutilização e reciclagem.

Neste contexto, destaca-se os resíduos vegetais que são mal utilizados, gerando grande quantidade de lixo orgânico, como cascas e sementes. Sendo estes, de fonte renovável, reciclável e produzidos em abundância em países tropicais como o Brasil (MERLINI, 2011, p. 25), abrem-se as possibilidades de pesquisas para concepções de novos materiais obtido destes resíduos e aplicados ao Design.

A busca destes materiais ecológicos tem resultado no desenvolvimento de compósitos derivados de produtos naturais, como frutas e fibras vegetais, combinado com uma matriz derivada de um polímero natural, como o óleo de mamona.

Para esta pesquisa, foram utilizadas fibras provindas do resíduo de corte de grama esmeralda, que tem origem japonesa e é a grama mais cultivada no Brasil, amplamente utilizada para jardins residenciais, campos de esporte e áreas industriais. Devido a enorme quantidade de biomassa vegetal pós corte dos gramados, é depositada e retirado todos os dias das grandes cidades brasileiras grande volume de biomassa residual. Em Curitiba, por exemplo, no período de janeiro e fevereiro de 2017, houve uma coleta de 2,5 mil toneladas de lixo vegetal (Portal da Prefeitura de Curitiba, 2017). Esse tipo de lixo é pouco aproveitado, em alguns casos se tornando adubo, porém seus principais destinos são terrenos baldios, lixões ou são queimados.

A partir de conceitos do Eco Design dada por Victor Papanek, onde se trata de uma abordagem que consiste em reduzir impactos ambientais (KAZAZIAN, 2005, p. 36), a pesquisa busca uma solução para unir novas possibilidades de design com um material sustentável e redução de resíduos orgânicos.

\section{FUNDAMENTAÇÃO TEÓRICA}

\subsection{O Design de Produto e os materiais}

$\mathrm{O}$ ritmo das mudanças que atingem nossas experiências em sociedade e o alcance e a profundidade das informações disponíveis exigidas é um grande desafio para o designer hodiernamente (MORRIS, 2010, p. 6). Percebe-se, então, que materialidade e eficiência combinadas permitem ao designer desenvolver produtos que sejam inovadores, com expressões tangíveis e otimizadas de uma ideia (MELLO,2015, p. 83).

O papel do designer é ver possibilidades em novos materiais, encontrar significados relevantes para as pessoas, habilitar a criação de novas experiências (ASHBY, 2011, p. 15), então a criação de um material pode ser o início de novas 'expressões' dentro do design. São os materiais que dão substância a tudo que vemos e tocamos, sendo um dos pontos mais importantes da escolha no projeto de design de produto. É necessário que ele traga todos os atributos que o designer deseja passar, tanto na funcionalidade técnica quanto na personalidade para o produto. Os consumidores são cada vez mais sensíveis a iniciativas para a economia de matérias-primas e energia, e a outras destinadas a facilitar a utilização e a manutenção do produto, como também a 
gestão dos resíduos em fim de vida (KAZAZIAN, 2005, p. 37).

A estética na sustentabilidade tem um papel fundamental. Pois, uma inovação ambientalmente sustentável, sem ser percebida como melhoria (comparada com soluções obsoletas), não é suficiente. Em outras palavras, deve ser esteticamente cativante. A estética neste caso, não implica apenas em cores e formas, mas em todo o conjunto de características percebidas que, de alguma forma, fazem com que o produto seja considerado mais atrativo (VEZZOLI, 2010, p. 49).

\subsection{Inovação em novos materiais}

A combinação entre o design de produto e a ciência dos materiais é um processo para achar soluções que sejam benéficas para as pessoas, gerando novos comportamentos, novas experiências, novas arquiteturas e criando um impacto positivo na sociedade e em nossa vida diária (MELLO, 2015, p. 82).

Novos materiais são apenas o ponto de partida, há muitas possíveis aplicações no design de produtos, superfícies inesperadas, experiências únicas, funções simples ou comportamentos significativos (ASHBY, 2011, p. 169). O que muitas vezes é esquecido é que os materiais possuem não apenas o apelo técnico como também pessoal, revelando um desafio frequente nesse setor industrial, lembrar do elemento humano e não focar apenas na tecnologia. Ashby (2011) ainda destaca que, o desafio de implantar novos materiais ou novos usos para materiais já criados, permanece, sendo dois deles: a lacuna de informações encontrada por designers que procuram usar novos materiais e a dificuldade que eles têm de estimular fornecedores a desenvolver materiais com os atributos desejados.

É comum dizer que os designers atendem as necessidades do mercado, mas às vezes é ele próprio quem as cria. Enquanto que a ciência é a força que tem o papel de revelar novas tecnologias, que estimulam novas oportunidades para o design.

\subsection{Materiais Compósitos}

De acordo com Callister (2002), os compósitos podem ser definidos como uma mistura física de dois ou mais materiais com composições, estruturas e propriedades diferentes que são combinados para formar um material constituído por duas ou mais fases, no caso a matriz, fase contínua e o material de reforço, fase dispersa.

O papel da matriz é manter a integridade estrutural do compósito, através de ligações com a fase dispersa (ou material de reforço). O material de reforço é, mais rígido e resistente que a matriz, já que sua função é melhorar as propriedades mecânicas do polímero (MERLINI, 2011, p. 29). Compósitos podem ser classificados em: reforçados com partículas, reforçados com fibras e os compósitos estruturais.

As fibras naturais estão disponíveis em grandes quantidades por todo o mundo e trata-se de um recurso renovável, apresentam propriedades mecânicas satisfatórias e desempenham outras funções, como isolante térmico e acústico. No Brasil, a biodiversidade e a grande quantidade de culturas agrícolas, contribuem para uma expressiva gama de possibilidades de matérias-primas a serem estudadas até mesmo para utilizarmos como reforço em compósitos. (MELLO, 2013, p. 88) 


\subsection{Poliuretano derivado do óleo de mamona}

Conhecidos desde 1849, os poliuretanos foram desenvolvidos para aplicação comercial na década de 1930 por Otto Bayer e colaboradores, e segundo Azevedo (2009) foi usado desde a 2a Guerra Mundial com aplicações em fibras, cerdas, revestimentos, espumas, adevisos e elastômeros.

Uma tendência global, segundo Vilar (2004), no mercado de PUs é a procura por polióis obtidos de fontes renováveis, como os à base de óleos naturais (NOPs), em função da substituição parcial de matérias-primas de origem petroquímica. Dentre estes NOPs usados na fabricação de PUs, tem-se os polióis derivados do óleo de mamona e os obtidos a partir de óleos vegetais poliinsaturados.

Os óleos vegetais são um recurso interessante para a formação do poliol que dá origem ao poliuretano, devido à presença de triglicerídeos em sua estrutura. Entre os possíveis óleos vegetas para este uso estão o óleo de mamona, óleo de soja, óleo de maracujá, entre outros. (MERLINI, 2011, p. 45). Segundo Vilar (2004) o óleo de mamona é um triglicerídeo presente em teores de 80 a $90 \%$ na semente da planta Ricinus Communis, com molécula descrita conforme Azevedo (2009), é comumente chamada de mamona e muito abundante em todo o território nacional. $\mathrm{O}$ óleo de mamona é um líquido viscoso, de odor forte, obtido pela prensagem das sementes.

O poliuretano derivado do óleo da mamona, ilustrado na Figura 12 , segundo Canjemi (2006) é um polímero biodegradável, na presença de microrganismos e não possuem compostos orgânicos voláteis. De acordo com Azevedo (2009), este poliuretano ainda tem a vantagem de o óleo de mamona não ser utilizado como alimento e não utilizarem um solvente orgânico, apresentando ainda ampla aplicação em diversas áreas da ciência.

\section{MATERIAL E MÉTODOS}

Os procedimentos utilizados neste trabalho se caracterizam como uma pesquisa aplicada experimental e interdisciplinar. Pois é movida pela contribuição para fins práticos, descreve os experimentos e envolve outras áreas do conhecimento além do Design, como a ciência dos materiais e a botânica.

Os equipamentos utilizados na fabricação do compósito foram: Estufa MedClave usada à $40^{\circ}$, prensa hidráulica Bovenau fria de 15 toneladas, balança digital FWB modelo 91379, pote plástico para a mistura, vaselina, folhas plásticas e luvas vinílicas), estruturas disponíveis no Laboratório de Polímeros e Compósitos (LAPOC) da UTFPR.

O poliuretano utilizado foi gentilmente fornecido pela empresa $\mathrm{KEHL}^{\circledR}$ Polímeros Industria e Comercio Ltda,. Apresenta-se na forma bicomponente, pré-polímero AG101A e um poliol AG101B. O pré-polímero é um líquido marrom escuro, insolúvel em água e o poliol é amarelado, solúvel e biodegradável.

A grama coletada foi do tipo Esmeralda (Zoysia Japônica), que possui folhas em forma de lança e boa resistência (Figura 1), obtida na cidade de em Curitiba. A partir da limpeza e seleção, as fibras foram levadas à estufa à $65^{\circ} \mathrm{C}$ por 72 horas para secagem à $5-8 \%$ de umidade. 0 compósito final foi produzido com 60 gramas de fibra de grama, adicionado $45 \mathrm{~g}$ (A) de poliol e $45 \mathrm{~g}$ (B) de pré-polímero, com prensagem à temperatura ambiente, sendo ciclo de prensagem em (i) pressão: 6 t e (ii) tempo de prensagem: 16 horas.

A caracterização de qualidade, através de ensaios de flexão e absorção de água, foi realizada em máquina universal de ensaios (EMIC) e observações microestruturais obtidas através 
de imagens de microscopia eletrônica de varredura (MEV), com apoio do Centro Multiusuário de Caracterização de Materiais.

Figura 1 - Grama limpa e triturada, respectivamente
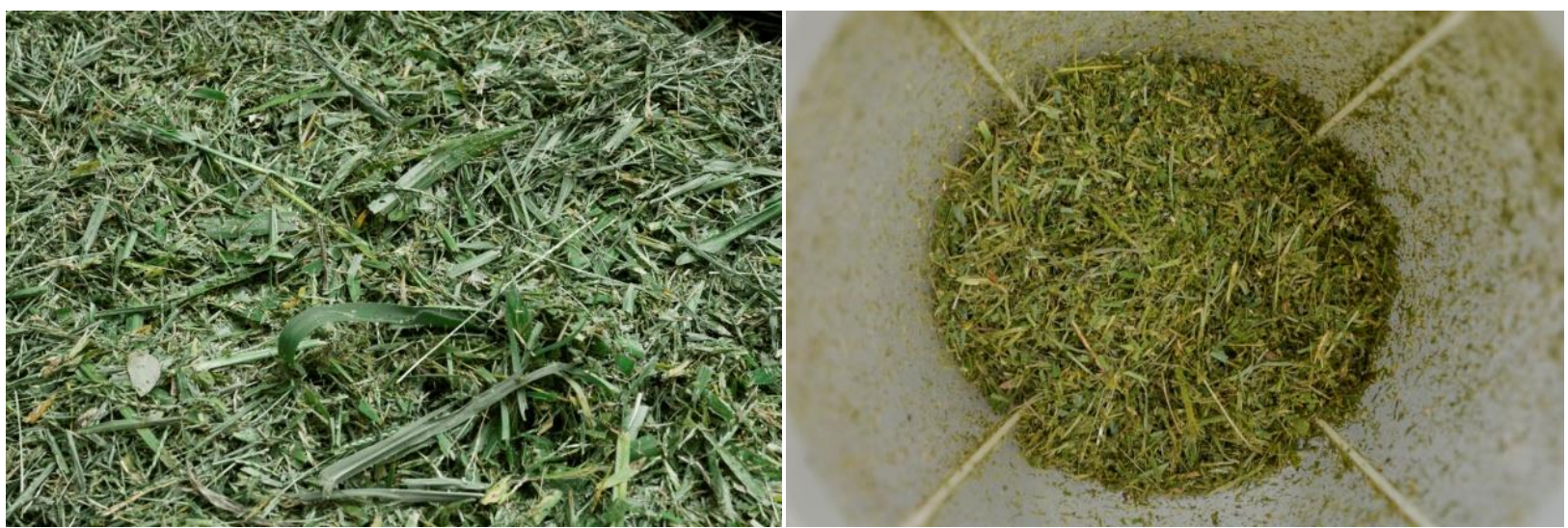

Fonte: Acervo do autor (2017)

\section{RESULTADOS}

\subsection{Resultados de ensaios de qualidade}

O resultado da avaliação dos compósitos confeccionados com grama mostrou-se inovador em Design de Produtos e muito motivador. Percebe-se, conforme a Figura 2, uma melhor união das fibras e maior adensamento superficial, resultando em melhor estrutura. A coloração da fibra foi realçada e preservada após a moldagem, trazendo um aspecto rústico ao material.

Figura 2 - Compósito de grama aglutinado com PU mamona.

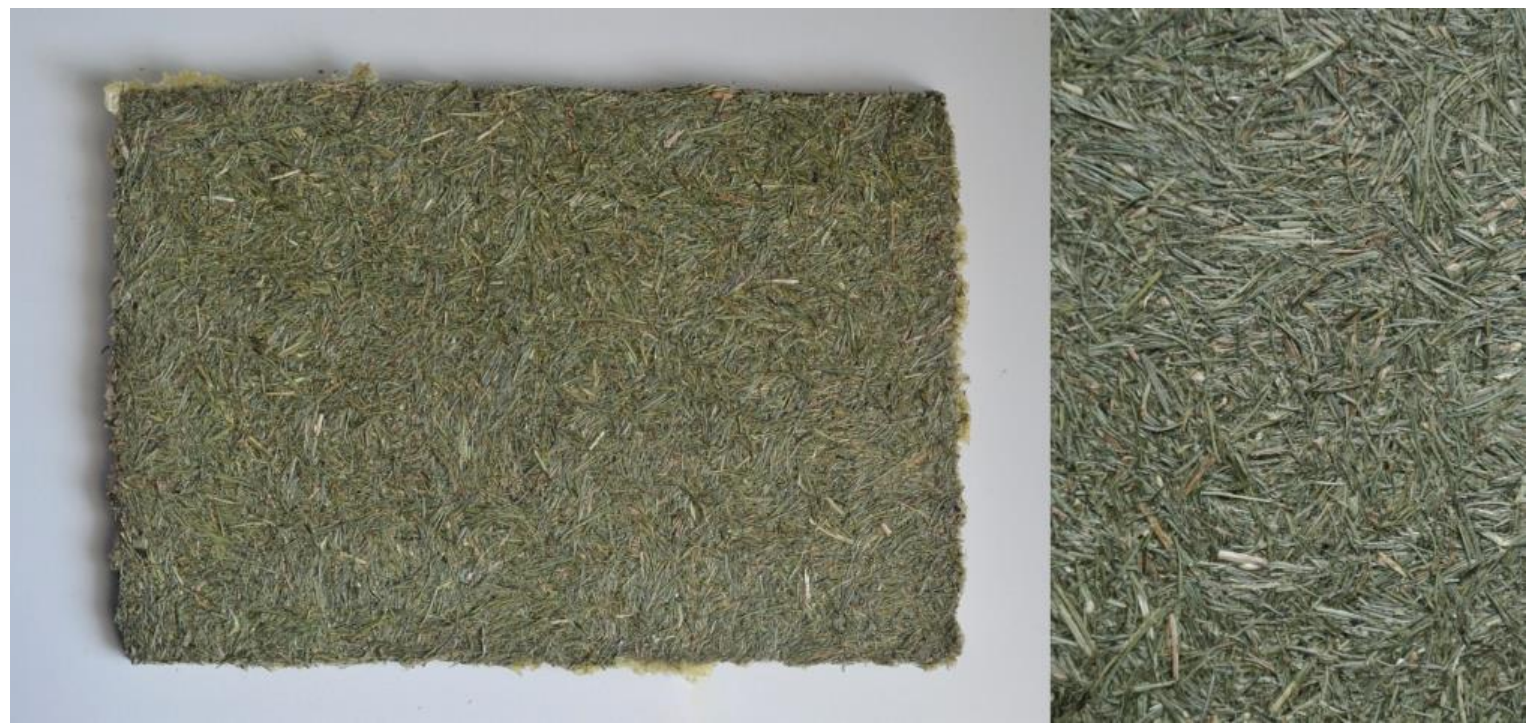

Fonte: Acervo do autor (2017) 
A Figura 3, obtida sob microscopia eletrônica de varredura (MEV), revela a estrutura da fibra, com faces lisas, o que ajudou à uma melhor aderência do poliuretano na interface parede fibra/PU. Percebe-se também a aderência do PU, através da visão da fibra fraturada e o PU espalhado em diversos espaços do compósito, resultando uma maior homogeneidade de mistura e aderência.

Figura 3 - Micrografia MEV do compósito de grama

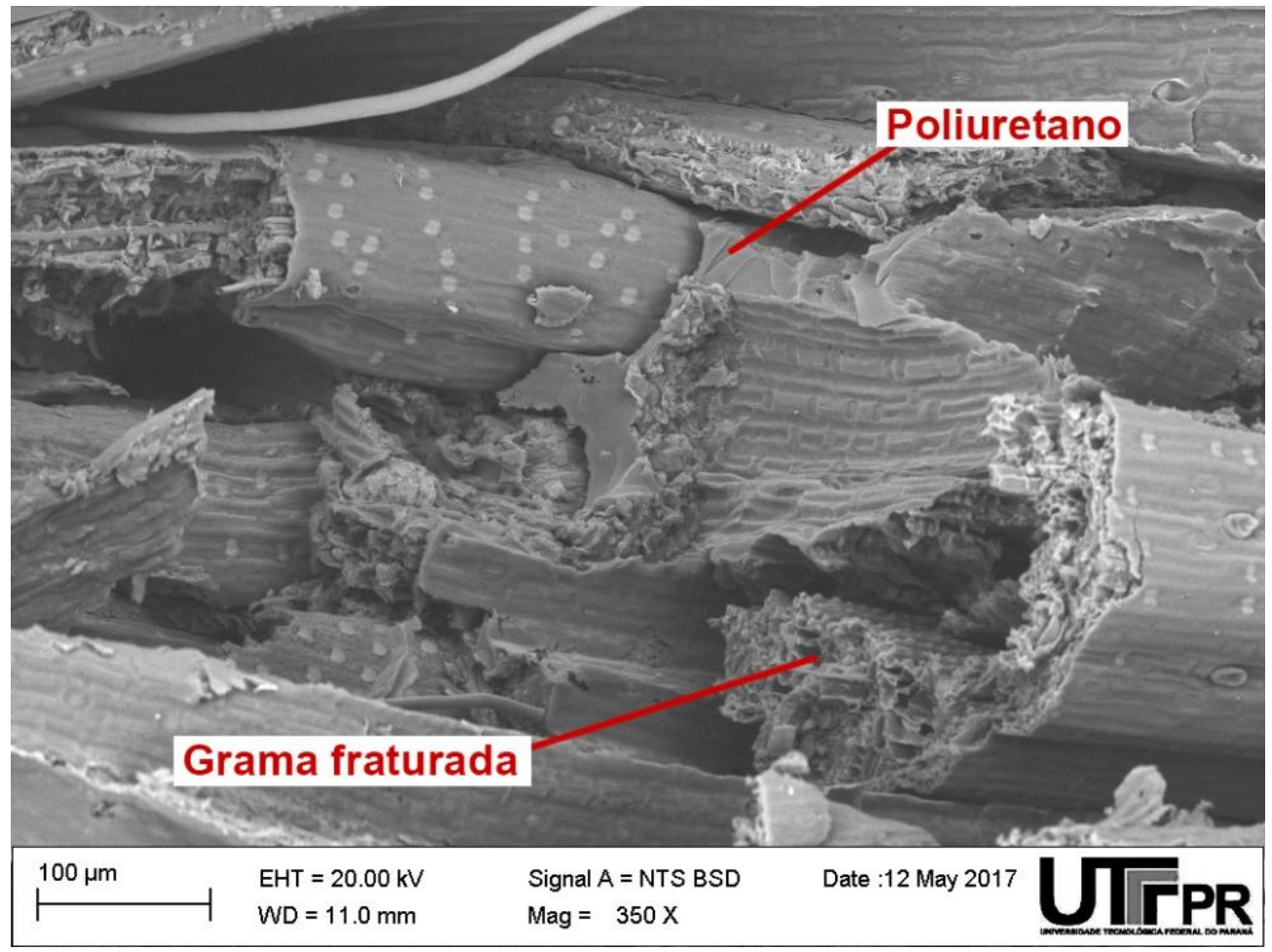

Fonte: Acervo do autor (2018)

Foram realizadas análises físico-mecânicos com o compósito de grama e, visando apenas tecer comparativo de grandeza de valores, e fortalecer a perspectiva do possível uso de compósitos tidos como mais frágeis, foram inseridos dados de compósitos confeccionados com matérias primas tradicionais (serragem de madeira e sisal).

O compósito de serragem foi obtido nas mesmas condições do compósito de grama, utilizando-se como matéria prima serragem oriunda de marcenaria. Quanto ao compósito de sisal, optou-se por adicionar para o comparativo o compósito produzido por Ferrazza (2012), onde o compósito foi constituído por cinco camadas de tecido de sisal, cada uma com $1 \mathrm{~mm}$ de espessura, e 30 gramas de poliuretano derivado do óleo de mamona para cada $64 \mathrm{~cm}^{2}$ de sisal, resultando em amostras com proporção de massa de $75 \%$ de sisal para $25 \%$ de poliuretano.

Devido à característica intrínseca às estruturas celulares da parede da folha de grama, aliados à uma pesquisa inovadora porém em estágios inicias de desenvolvimento, observa-se através da Tabela 1 que o compósito grama + PU mamona apresentou valores inferiores de tensão média mas que, cita-se com relevância, não foi problema para experimentação em material e concepção de uma proposta sólida de utilização deste compósito através de preceitos aliados entre desenvolvimento de produtos de Ecodesign. Cita-se ainda, como aspecto positivo, o baixo 
desvio padrão dos valores obtidos para o compósito de grama + PU mamona, resultando em boa homogeneidade entre uma amostra e outra e fidelidade na confecção de repetidas amostras.

Tabela 1 - Comparativo entre resultados de flexão nos compósitos de Grama/Serragem/Sisal - 2017

\begin{tabular}{cccc}
\hline & Grama & Serragem & Sisal \\
\hline $\begin{array}{c}\text { Tensão } \\
\text { Média (Mpa) }\end{array}$ & 13.34 & 28.45 & 69.55 \\
\hline Desv. Padrão & 1.30 & 3.78 & 12.69 \\
\hline
\end{tabular}

\section{Fonte: Autoria própria, 2017.}

Por fim, foi realizado ensaio de absorção de água nos compósitos de grama e serragem, onde os corpos de prova foram submersos por $24 \mathrm{hrs}$, e então coletados os dados da massa absorvida em 2 horas e 24 horas, que são indicados na Tabela 2.

Tabela 2 - Comparativo entre resultados de absorção de água - 2017

\begin{tabular}{ccc} 
& Grama & Serragem \\
\hline 2 horas & $6,31 \%$ & $2,20 \%$ \\
\hline 24 horas & $12,69 \%$ & $4,94 \%$ \\
\hline
\end{tabular}

Fonte: Autoria própria, 2017.

A absorção de água pelo compósito de grama foi maior que o de serragem, devido principalmente aos maiores espaços vazios, corroborando com o verificado na Figura 3 mas que, complementando o discutido durante interpretações dos valores de flexão, não invalidou proposta sólida de projeto com o compósito. Após a avaliação dos compósitos, em quesitos mecânicos, físicos, estéticos e inovadores, foi necessário avaliar as possibilidades de aplicações do material. Para o desenvolvimento de um produto, foi adotado um procedimento metodológico básico, mas essencial, apenas para avaliar as aplicações do compósito.

\subsection{Requisitos em experimentação do material e Design de Produto}

Os conceitos e requisitos foram escolhidos com base no material. Trazendo a importância do EcoDesign e da Sustentabilidade, motivado pelo impacto ao meio ambiente e a vida útil. A rusticidade, devido as texturas, imperfeições do material e elementos naturais, remetendo a uma atmosfera aconchegante. Funcionalidade e fácil manuseio serão aplicados motivados pela busca de objetos que não sejam apenas decorativos, mas que sejam realmente utilizados no dia-a-dia das pessoas.

A partir destes requisitos foi realizado um brainstorming de possíveis aplicações do compósito (Figura 4), considerando apenas suas características, abrangendo diversas áreas do Design. Dentre as diversas opções, optou-se pela luminária para a experimentação dos compósitos 
de grama (Figura 5) e posterior fabricação de um protótipo, pois este elemento tem possibilidade de apresentar melhor o material, com potencial para mostrar todos os conceitos, requisitos e poder ser confeccionado com as ferramentas e materiais disponíveis, além de tratar-se de um objeto de alto valor agregado remetendo a um produto de maior valor agregado (PMVA).

Figura 4 - Brainstorming de geração de alternativas

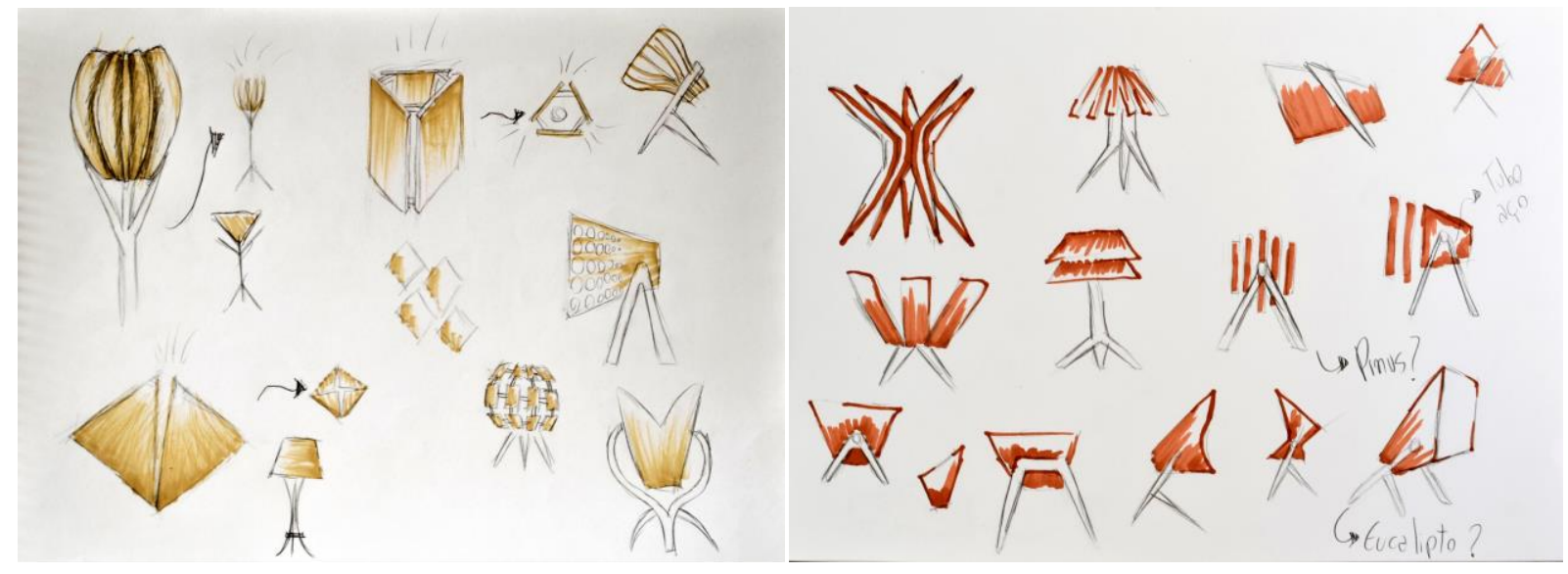

Fonte: Autoria própria (2017)

Figura 5 - Protótipo da luminária feita com compósito de grama e estrutura em madeira reciclada de pinus.

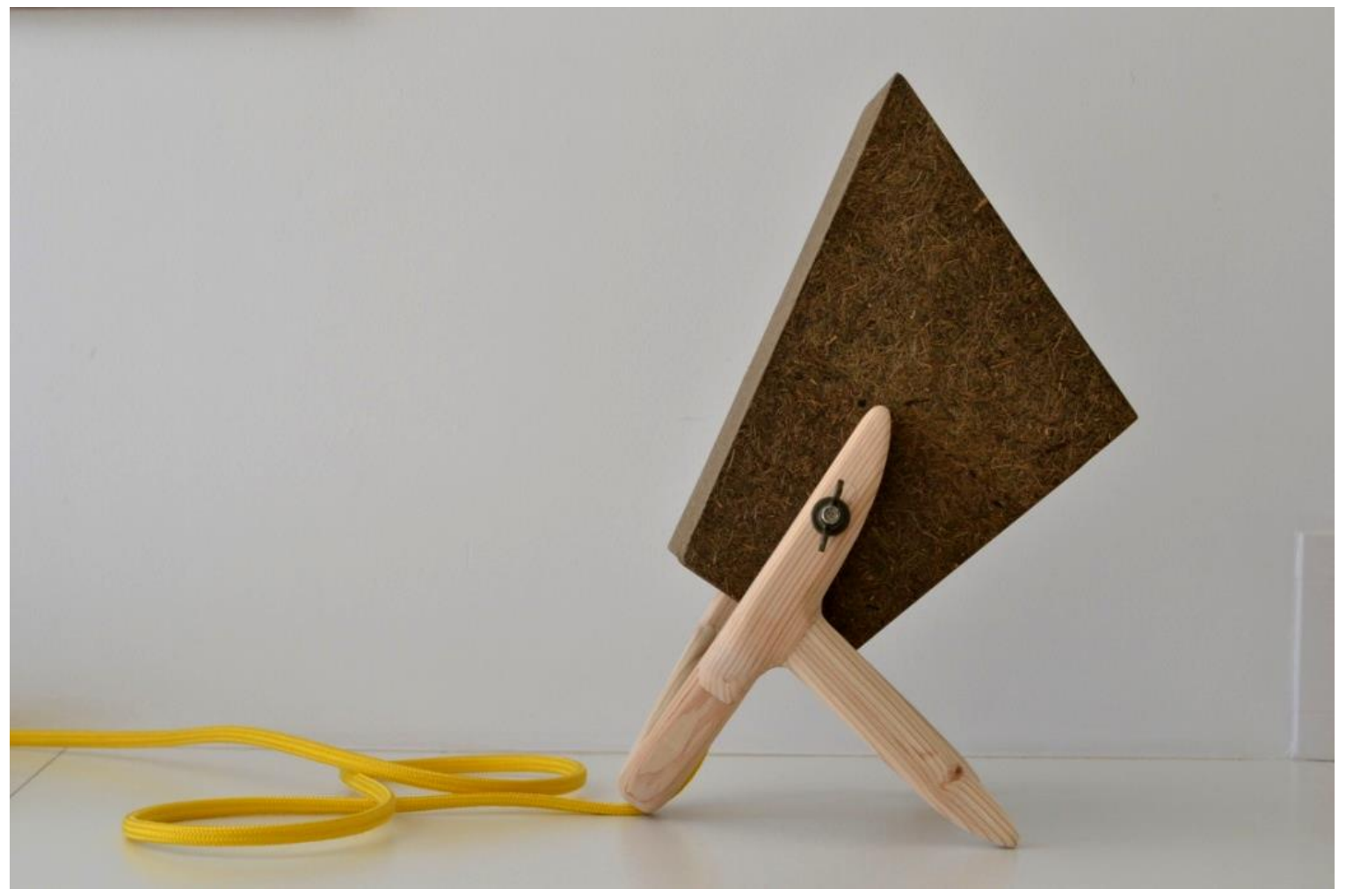

Fonte: Autoria própria (2017) 


\section{Artigo Completo}

Para visualizar o uso da luminária, esta foi disposta em possíveis cenas do dia-a-dia. Podendo ser usada como abajur, iluminando suavemente o canto de um quarto, dando destaque para quadros, usada como luminária de leitura ou como luz ambiente, conforme Figuras 6 e 7.

Figura 6 - Luminária para luz ambiente

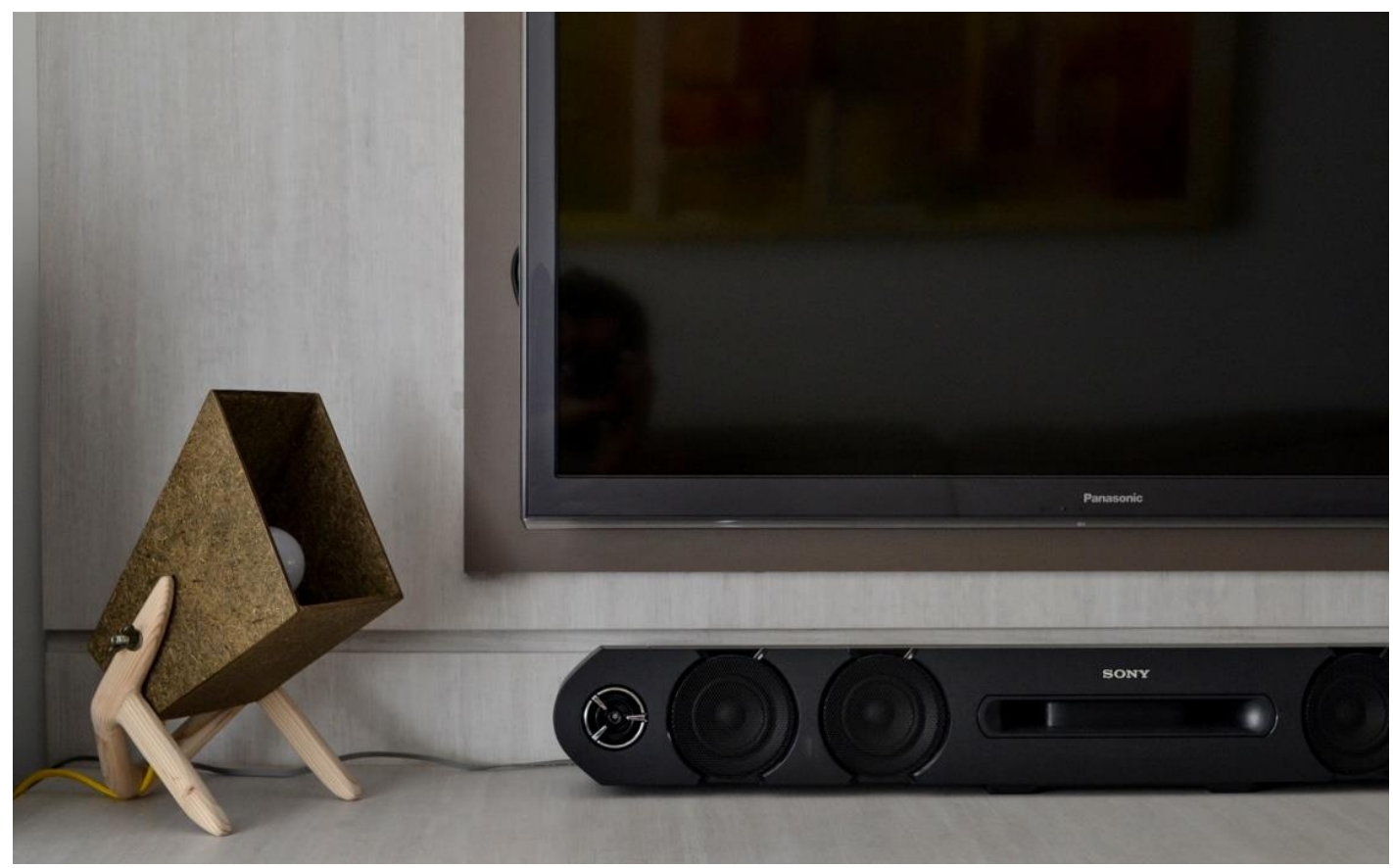

Fonte: Autoria própria (2017)

Figura 7 - Abajur com luz direcional

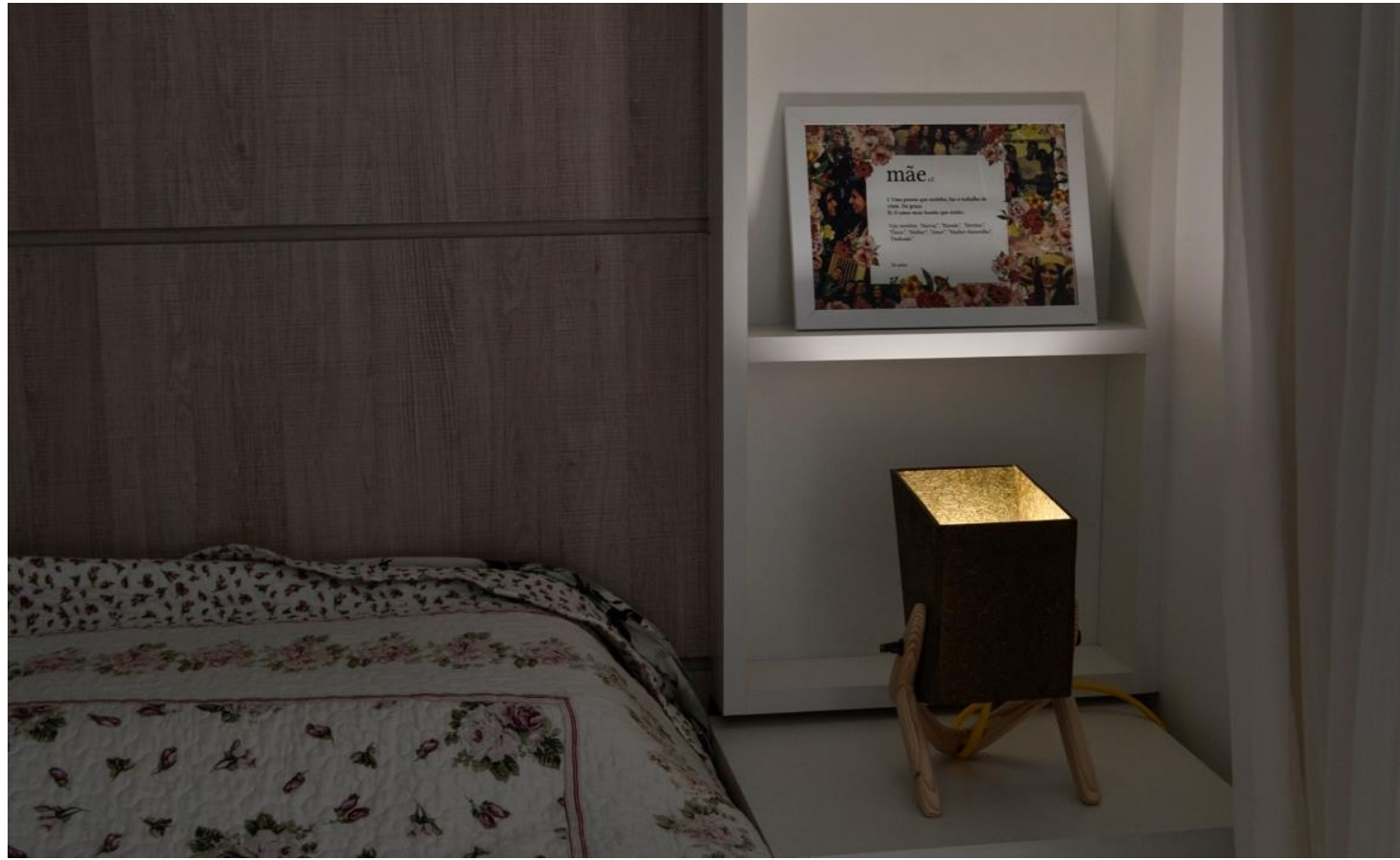

Fonte: Autoria própria (2017)

13 Congresso Brasileiro de Pesquisa e Desenvolvimento em Design, Univille, Joinville (SC)

05 a 08 de novembro de 2018 


\section{CONSIDERAÇÕES FINAIS}

Este trabalho teve como objetivo inicial do desenvolvimento de um compósito biodegradável e ecológico utilizando-se de biomassa de grama, recurso lignocelulósico comumente descartado no processo pós corte. Apresentando-se como recurso fibroso de baixo custo e grande disponibilidade, e através de delineamento de confecção e perspectiva de obtenção de novo objeto foram obtidos compósitos com qualidade e visual bastante atrativo.

Indica-se, com destaque, que mesmo com valores inferiores em ensaio de flexão, comparativamente à compósitos confeccionados com matérias primas tradicionais, como serragem de madeira e sisal, não houve problema para experimentação em material e concepção de uma proposta sólida de utilização deste compósito através de preceitos aliados entre desenvolvimento de produtos de Ecodesign. Este resultado é fundamental e incentivador, pois indica-se a concepção de um produto de alto valor agregado (PVMA) para uso interno, comprovando que o compósito tem capacidade para amplas aplicações nas áreas de Design e Bioengenharia.

A viabilidade de se produzir este compósito em grande escala também pode ser considerada. Devido a aspectos de sustentabilidade do poliuretano (PU), que é livre de formol, e haver ampla possibilidade de obtenção de grama pós corte em amplitude nacional, pode-se, por exemplo, prever parceria com prefeituras para fornecimento da grama pós corte como recurso fibroso.

Este foi um estudo pioneiro propondo a utilização de resíduos de corte de grama para a concepção de um compósito totalmente novo. Sabendo do seu potencial em diversas questões já apresentadas, recomenda-se para trabalhos futuros aperfeiçoar seu ciclo de obtenção e prensagem, suas especificações técnicas e confeccionar placas com dimensões maiores para avaliar novos usos e aplicações.

\section{REFERÊNCIAS}

ASHBY, Michael F; JOHNSON, Kara. Materiais e Design: Arte e ciência da seleção de materiais no design do produto. 2 ed. Rio de Janeiro: Elsevier, 2011.

AZEVEDO, Elaine C. Efeito da radiação nas propriedades mecânicas do adesivo de poliuretana derivado do óleo de mamona. 2009. 134 p. Tese (Doutorado em Ciência e Engenharia de Materiais) - Setor de Tecnologia, Universidade Federal do Paraná, Curitiba, 2009.

CALLISTER JR., Willian. Ciência e engenharia de materiais: Uma introdução. 5 ed. Rio de Janeiro: LTC, 2002.

KAZAZIAN, Thierry. Haverá a Idade das Coisas Leves: Design e Desenvolvimento Sustentável. 2. ed. São Paulo: Senac, 2005. 
MARCHETTO, Adriana et al. Avaliação das partes desperdiçadas de alimentos no setor de hortifruti visando seu reaproveitamento. Revista Simbio-Logias, v. 1, n. 2, p. 1-14, Nov/2008. Disponível em: <http://www.ibb.unesp.br/Home/Departamentos/Educacao/Simbio-Logias/artigo_nutr_ avaliacao_partes_desperdicadas_alimentos_setor.pdf > Acesso em: 21 ago. 2016.

MELLO, Anne K. Design de tecnologia social: Reaproveitamento do ouriço da castanha do Brasil no desenvolvimento de novos materiais. 2013. 134 f. Dissertação (Mestrado em Design) Pontifícia Universidade Católica do Rio de Janeiro, Rio de Janeiro, 2013.

MERLINI, Claudia. Análise experimental de compósitos de poliuretano derivado de óleo de mamona e fibras de bananeira. 2011. 104 f. Dissertação (Mestrado em Ciência e Engenharia de Materiais) - Universidade Federal de Santa Catarina, Centro Tecnológico, Florianópolis, 2011.

MORRIS, Richards. Fundamentos de Design de Produto. 1 ed. Porto Alegre: Bookman, 2010.

PORTAL DA PREFEITURA DE CURITIBA. Combate à dengue ganha força com coleta de $\mathbf{2 , 5}$ mil toneladas de lixo vegetal. Disponível em: <http://www.curitiba.pr.gov.br/noticias/ combate-a-dengue-ganha-forca-com-coleta-de-25-mil-toneladas-de-lixo-vegetal/41114>. Acesso em: 23 abr. 2017.

VEZZOLI, Carlo. Design de Sistemas para a Sustentabilidade: Teoria, métodos e ferramentas para o design sustentável de "sistemas de satisfação". Salvador: EDUFBA, 2010.

VILAR, Walter. Química e Tecnologia de Poliuretanos. 3 ed. Rio de Janeiro: Vilar Consultoria, 2004. 